OPEN ACCESS

Edited by:

Samar A. Ahmed,

Ain Shams University, Egypt

Reviewed by:

Shailesh Lele,

Shri Dashabhuja Health Services Pvt.

Ltd., India

Gehan Sadek

Menoufia Faculty of Medicine, Egypt

*Correspondence:

Koji Naruish

naruishi@tokushima-u.ac.jp

Specialty section:

This article was submitted to

Systems Integration,

a section of the journal

Frontiers in Dental Medicine

Received: 15 September 2021 Accepted: 20 December 2021

Published: 12 January 2022

Citation:

Naruishi K, Wada-Mihara C, Oishi K and Nagata $T$ (2022) Dental Students'

Awareness After Clinical Training

Between Dental Treatment and

Systemic Health: A

Questionnaire-Based Survey.

Front. Dent. Med. 2:740441.

doi: 10.3389/fdmed.2021.740441

\section{Dental Students' Awareness After Clinical Training Between Dental Treatment and Systemic Health: A Questionnaire-Based Survey}

\author{
Koji Naruishi*, Chie Wada-Mihara, Keiji Oishi and Toshihiko Nagata \\ Department of Periodontology and Endodontology, Tokushima University Graduate School of Biomedical Sciences, \\ Tokushima, Japan
}

Clinical training is an essential program for dental students to learn clinical skills. The aim of this study was to survey whether dental students who had undergone clinical training understood the clinical significance of dental treatment and its connection to systemic health. An awareness survey was conducted in dentistry students both before and after undergraduate clinical training. A total of 42 dental students were recruited before clinical training, and 32 dental students responded to the survey. In addition, all of the 42 dental students responded to the survey after clinical training. A total of 53 medical students were recruited as control subjects. Differences between the 2 groups were analyzed using Fisher's exact test. Before clinical training, a higher percentage of dental students felt the positive effects of periodontal treatment on systemic health. A higher percentage of dental students also recognized the positive effects of prosthetic treatment on geriatric conditions. After clinical training, no significant differences were found between periodontal and prosthetic treatment when surveyed about the positive effects of dental treatment on geriatric conditions. Undergraduate clinical training is essential for improving the students' understanding of the clinical significance of dental treatment. These surveys suggest that dental education supported by clinical experience contributes to understand the role of dental treatment.

Keywords: dental education in Japan, undergraduate clinical training, dental treatment, awareness survey, geriatric

\section{INTRODUCTION}

Marked progress in dental treatment has been made worldwide, and the level of dental education for students has steadily risen. Research has contributed to an improvement in the educational standards not only in the dental field but also in the medical field $(1,2)$. Periodontal disease has a negative influence on systemic diseases such as diabetes mellitus, rheumatoid arthritis, and arteriosclerosis (3, 4). In addition, the occurrence of aspiration pneumonia is exacerbated by "oral frailty" such as swallowing disorders 
and poor oral hygiene in older adults (5). An unclosed mouth and impaired tongue movements, which are related to the strength of the oral muscles, are also associated with a higher incidence of aspiration pneumonia (6). Stable occlusion is an important factor to prevent the oral frailty. Therefore, prosthetic treatment is an effective indirect treatment for preventing the occurrence of aspiration pneumonia in older adults (7).

Loss of posterior occlusion is an unwanted consequence of periodontitis progression, and impairment of the masticatory muscles may gradually occur in older people without dentures (8). In these elderly patients, oral pathogens readily lodge into their bronchial tubes, which leads to the development of aspiration pneumonia. In addition, periodontal treatment prevents tooth loss and enables the consumption of more enjoyable meals, which supports overall nutrition (9). Therefore, both periodontal and prosthetic treatments have, directly or indirectly, positive effects on the prevention of aspiration pneumonia. Dental students should be taught that periodontal treatment is essential not only for the improvement of systemic diseases in middle-aged people, but also the stability of posterior occlusions for the prevention of aspiration pneumonia in elderly people. Ultimately, the therapeutic goal of periodontal treatment is to contribute to the systemic health of people in different age groups.

In Japan, dental students learn basic medical and dental science during the first 4 years of their undergraduate curriculum. The first encounter with patients during undergraduate clinical training is a key part of the undergraduate program in dental universities. The students learn to prevent, diagnose and treat various oral diseases such as periodontitis and tooth loss. However, it is necessary to evaluate whether the dental students have fully understood the significance of dental treatment for systemic health of patients in different ages. In the present study, we surveyed the changes in awareness of undergraduate dental students before and after clinical training in the clinical significance of dental treatment.

\section{UNDERGRADUATE CLINICAL TRAINING}

There are 2 main teaching/learning methods: traditional lectures and clinical training in the undergraduate educational curriculum of dentistry. Traditionally, a teacher/instructor lectures in front of the classroom. This is frequently termed "teacher-centered education", because the students are expected to sit and listen quietly. On the other hand, clinical dental training after a lecture course is student-centered. During their undergraduate clinical training courses, dental students are supervised by some professionals, and actively involved in the treatment of patients. Clinical training is an essential program for elevating the clinical skills of dental students, contributing to deepening their knowledge studied in their lectures, heightening their sense of both responsibility and cooperation, and developing their clinical thinking.

The 5-6th year dental students see patients for 1 year at our university hospital as undergraduate clinical course. They have firsthand experience of the dental care from the medical interview at first visit to the maintenance phase after treatment under the guidance of seasoned instructors for procedures, i.e., simple tooth extraction, basic periodontal and prosthetic treatment.

\section{SUBJECTS AND AWARENESS SURVEY FOR THIS STUDY}

An awareness survey of dental students before and after clinical training at Tokushima University Hospital was performed during the 2018-19 academic year for the effects of periodontal or prosthetic treatment on diseases, symptoms, and conditions. A total of 42 dental students (male: 27, female: 15) before clinical training were recruited, and 32 dental students (male: 22, female: 10) responded to the survey. In addition, all of the 42 dental students responded to the survey after completion of clinical training. As control subjects, a total of 55 Tokushima University medical students (4th-year students before clinical training) were recruited, and 53 medical students (male: 25, female: 28) responded to the survey. The medical students had not received any lectures about dental treatment.

A written informed consent form was signed by every student involved in this study. The questionnaire was anonymous, and students were allowed to decline or withdraw from participation at any time without any negative consequences. This study was approved by the ethics committee of Tokushima University Hospital (No. 3454). The results of this questionnaire were tallied immediately, and the outcomes were calculated as percentages of the available responses. The results were analyzed by Fisher's exact test. Statistical analyses were performed, and $P$-values of $<0.05$ were considered significant.

\section{DIFFERENCES OF THR AWARENESS SURVEY RESULTS BETWEEN DENTAL AND MEDICAL STUDENTS FOR THE EFFECTS OF DENTAL TREATMENT ON SYSTEMIC HEALTH}

As shown in Table 1, the percentage of dental students who recognized that periodontal treatment has positive effects on systemic diseases (diabetes mellitus: $P=0.013$, arteriosclerosis: $P=0.0007$, cerebrovascular disorder: $P=0.013$, aspiration pneumonia: $P=0.020$ ) was statistically higher than that of the medical students. On the other hand, no significant differences were found between dental and medical students in the recognition of the effects of periodontal treatment on oral-, geriatric-, and feelings of happiness-related factors. There were no significant differences between dental and medical students in almost all of the survey items concerning the effects of prosthetic treatment; however, the percentage of medical students who recognized that prosthetic treatment has a positive effect on halitosis $(P=0.044)$ was statistically higher than that of dental students. 
TABLE 1 | An awareness survey of dental and medical students before clinical training about the effects of periodontal or prosthetic treatment on diseases, symptoms, and conditions.

\begin{tabular}{|c|c|c|c|c|c|c|}
\hline \multirow[t]{3}{*}{ Survey item } & \multicolumn{6}{|c|}{ Considered positive effects (\%) } \\
\hline & \multicolumn{3}{|c|}{ Periodontal treatment } & \multicolumn{3}{|c|}{ Prosthetic treatment } \\
\hline & $\begin{array}{l}\text { Dental students } \\
\qquad(N=32)\end{array}$ & $\begin{array}{c}\text { Medical } \\
\text { students }(N=53)\end{array}$ & $P$-value & $\begin{array}{l}\text { Dental students } \\
\qquad(N=32)\end{array}$ & $\begin{array}{c}\text { Medical } \\
\text { students }(N=53)\end{array}$ & $P$-value \\
\hline \multicolumn{7}{|l|}{ Oral: } \\
\hline Not extracted & 100 & 94.3 & 0.17 & 75.0 & 83.0 & 0.37 \\
\hline Halitosis & 68.8 & 83.0 & 0.13 & 43.8 & 66.0 & $0.044^{*}$ \\
\hline \multicolumn{7}{|l|}{ Systemic diseases: } \\
\hline Obesity & 65.6 & 43.4 & 0.088 & 53.1 & 58.5 & 0.63 \\
\hline Diabetes mellitus & 81.3 & 54.7 & $0.013^{\star}$ & 50.0 & 49.1 & 0.93 \\
\hline Stomach cancer & 56.3 & 60.4 & 0.71 & 46.9 & 45.3 & 0.89 \\
\hline Arteriosclerosis & 71.9 & 34.0 & $0.0007^{\star \star}$ & 43.8 & 35.9 & 0.47 \\
\hline Cerebrovascular disorder & 65.6 & 37.7 & $0.013^{\star}$ & 43.8 & 34.0 & 0.37 \\
\hline Pustulosis palmoplantaris & 25.0 & 32.1 & 0.49 & 31.3 & 22.6 & 0.38 \\
\hline Arthritis rheumatoid & 56.3 & 35.9 & 0.066 & 37.5 & 32.1 & 0.61 \\
\hline Chronic kidney disease & 43.8 & 32.1 & 0.28 & 37.5 & 34.0 & 0.74 \\
\hline Non-alcoholic steatohepatitis & 37.5 & 20.8 & 0.092 & 34.4 & 26.4 & 0.44 \\
\hline Aspiration pneumonia & 84.4 & 60.4 & $0.020^{\star}$ & 59.4 & 64.2 & 0.66 \\
\hline \multicolumn{7}{|l|}{ Geriatric: } \\
\hline Eating/swallowing function & 75.0 & 69.8 & 0.61 & 87.5 & 81.1 & 0.24 \\
\hline Eating function & 87.7 & 79.3 & 0.33 & 93.8 & 86.8 & 0.31 \\
\hline Swallowing function & 78.1 & 71.7 & 0.51 & 93.8 & 83.0 & 0.15 \\
\hline Walking function & 43.8 & 35.9 & 0.47 & 50.0 & 43.4 & 0.55 \\
\hline Nutritional condition & 75.0 & 77.4 & 0.80 & 84.4 & 81.1 & 0.70 \\
\hline Cognitive function & 62.5 & 56.6 & 0.59 & 81.3 & 66.0 & 0.13 \\
\hline \multicolumn{7}{|l|}{ Feelings of happiness: } \\
\hline Quality of life & 84.4 & 84.9 & 0.95 & 90.6 & 84.9 & 0.45 \\
\hline Healthy life expectancy & 90.6 & 84.9 & 0.45 & 84.4 & 83.0 & 0.87 \\
\hline
\end{tabular}

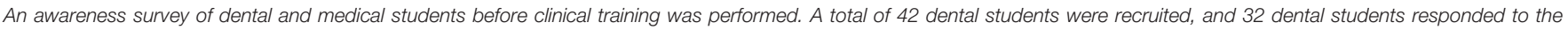

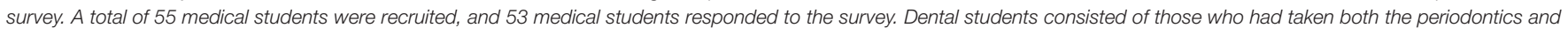

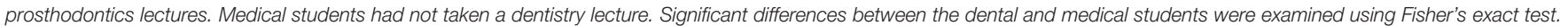
", $P<0.05$; ${ }^{\star *}, P<0.01$. The boldface indicates the "significantly higher" results.

\section{COMPARISON BEFORE AND AFTER CLINICAL TRAINING OF DENTAL STUDENTS' RECOGNITION}

Higher percentage of dental students recognized statistically the positive effects of periodontal treatment on systemic diseases after clinical training (diabetes mellitus: $P=0.017$, pustulosis palmoplantaris: $P=0.047$, aspiration pneumonia: $P=0.039$ ) (Table 2). The students also recognized the positive effects of both periodontal and prosthetic treatment on geriatric conditions (periodontal, nutritional function: $P=0.0006$, cognitive function: $P=0.0001$; prosthetic, nutritional function: $P=0.008$, cognitive function: $P=$ $0.003)$. There were no significant differences before and after clinical training in the students' recognition of the effects of prosthetic treatment on systemic diseases (diabetes mellitus, $P=0.06$, pustulosis palmoplantaris, $P=0.69$ ). A significant difference was found in the students' recognition of the effect of prosthetic treatment on aspiration pneumonia $(P=0.0005)$.

As expected, before clinical training, the dental students recognized statistically that periodontal treatment is important for preventing various systemic diseases such as diabetes mellitus $(P=0.018)$, arteriosclerosis $(P<0.0001)$, rheumatoid arthritis $(P=0.028)$, and chronic kidney disease $(P=0.0008)$, compared with prosthetic treatment (Table 3). Furthermore, the students recognized statistically that prosthetic treatment is more important for improving geriatric conditions, such as swallowing disorders $(P=0.042)$, walking function $(P=0.001)$, nutritional condition $(P=0.002)$, and cognitive function $(P=$ 0.019 ), compared with periodontal treatment. Fortunately, most dental students recognized that there are positive effects of both periodontal and prosthetic treatment on the quality of life or healthy life expectancy.

Finally, we surveyed the same subjects after completion of clinical training to evaluate the effects of their education. 
TABLE 2 | Changes in awareness of dental students after clinical training about the effects of periodontal or prosthetic treatment on diseases, symptoms, and conditions.

\begin{tabular}{|c|c|c|c|c|c|c|}
\hline \multirow[t]{3}{*}{ Survey item } & \multicolumn{6}{|c|}{ Considered positive effects (\%) } \\
\hline & \multicolumn{3}{|c|}{ Periodontal treatment } & \multicolumn{3}{|c|}{ Prosthetic treatment } \\
\hline & $\begin{array}{l}\text { Before clinical } \\
\text { training } \\
(N=32)\end{array}$ & $\begin{array}{l}\text { After clinical } \\
\text { training } \\
(N=42)\end{array}$ & $P$-value & $\begin{array}{l}\text { Before clinical } \\
\text { training }(N=32)\end{array}$ & $\begin{array}{c}\text { After clinical } \\
\text { training }(N=42)\end{array}$ & $P$-value \\
\hline \multicolumn{7}{|l|}{ Oral: } \\
\hline Not extracted & 100 & 100 & NE & 75.0 & 100 & $0.0006^{* *}$ \\
\hline Halitosis & 68.8 & 100 & $0.0001^{\star \star}$ & 43.8 & 73.8 & $0.009^{\star \star}$ \\
\hline \multicolumn{7}{|l|}{ Systemic diseases: } \\
\hline Obesity & 65.6 & 78.6 & 0.13 & 53.1 & 69.0 & 0.16 \\
\hline Diabetes mellitus & 81.3 & 97.6 & $0.017^{*}$ & 50.0 & 71.4 & 0.06 \\
\hline Stomach cancer & 56.3 & 54.8 & 0.90 & 46.9 & 40.5 & 0.58 \\
\hline Arteriosclerosis & 71.9 & 81.0 & 0.36 & 43.8 & 52.4 & 0.46 \\
\hline Cerebrovascular disorder & 65.6 & 76.2 & 0.32 & 43.8 & 52.4 & 0.46 \\
\hline Pustulosis palmoplantaris & 25.0 & 47.6 & $0.047^{\star}$ & 31.3 & 35.7 & 0.69 \\
\hline Arthritis rheumatoid & 56.3 & 69.0 & 0.26 & 37.5 & 38.1 & 0.96 \\
\hline Chronic kidney disease & 43.8 & 59.5 & 0.18 & 37.5 & 28.6 & 0.42 \\
\hline Nonalcoholic steatohepatitis & 37.5 & 47.6 & 0.38 & 34.4 & 28.6 & 0.59 \\
\hline Aspiration pneumonia & 84.4 & 97.6 & $0.039^{*}$ & 59.4 & 92.9 & $0.0005^{\star *}$ \\
\hline \multicolumn{7}{|l|}{ Geriatric: } \\
\hline Eating/Swallowing function & 75.0 & 95.2 & $0.011^{*}$ & 87.5 & 95.2 & 0.43 \\
\hline Eating function & 87.7 & 97.6 & 0.086 & 93.8 & 95.2 & 0.78 \\
\hline Swallowing function & 78.1 & 95.2 & $0.026^{\star}$ & 93.8 & 95.2 & 0.78 \\
\hline Walking function & 43.8 & 69.0 & $0.029^{\star}$ & 50.0 & 78.6 & $0.01^{*}$ \\
\hline Nutritional condition & 75.0 & 100 & $0.0006^{\star \star}$ & 84.4 & 100 & $0.008^{\star *}$ \\
\hline Cognitive function & 62.5 & 97.6 & $0.0001^{\star \star}$ & 81.3 & 100 & $0.003^{\star *}$ \\
\hline \multicolumn{7}{|l|}{ Feelings of happiness: } \\
\hline Quality of life & 84.4 & 100 & $0.008^{\star \star}$ & 90.6 & 100 & $0.043^{\star}$ \\
\hline Healthy life expectancy & 90.6 & 100 & $0.043^{*}$ & 84.4 & 97.6 & $0.039^{\star}$ \\
\hline
\end{tabular}

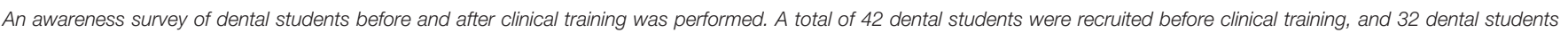

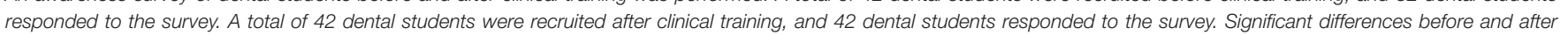
clinical training were examined using Fisher's exact test. ", $P<0.05 ;{ }^{* *}, P<0.01$. NE, not examined. The boldface indicates the "significantly higher" results.

The dental students after clinical training still recognized statistically that periodontal treatment is more important for preventing systemic diseases, such as diabetes mellitus $(P=$ $0.0009)$, arteriosclerosis $(P=0.006)$, rheumatoid arthritis $(P$ $=0.005)$, and chronic kidney disease $(P=0.004)$, compared with prosthetic treatment. However, no significant difference was found in the students' recognition of the role of periodontal treatment in preventing pustulosis palmoplantaris, even after clinical training. In the survey concerning geriatric conditions, importantly, no significant differences between the students' recognition of the role of periodontal and prosthetic treatment were found after clinical training. Most dental students after clinical training recognized that there are positive effects on geriatric conditions not only as a result of prosthetic treatment but also periodontal treatment.

\section{DISCUSSION}

Dental patients with systemic diseases that require an accurate knowledge of the pathogenesis have been increasing $(10,11)$.
Also, dental treatment can contribute to an improvement not only in oral conditions but also in feelings of happiness of the patients $(12,13)$. We think the benefits of dental treatment must be educated effectively to dental students. Therefore, we surveyed whether the undergraduate students at dental school understood the significance of periodontal and prosthetic treatment in the systemic health of patients.

At first, the educational effects of traditional lectures on the dental students' understanding of the positive relationship between systemic health and dental treatment were surveyed. Importantly, most dental students noticed the effects of periodontal treatment, but not prosthetic treatment on several systemic diseases compared with the medical students (Table 1), one of the most important topics in the field (3). This survey may indicate that traditional lectures before clinical training are useful to help students recognize the importance of periodontal treatment on systemic improvement. Interestingly, there were no significant differences between dental and medical students in the recognition of the effects of dental treatment on geriatric- and feelings of happiness-related factors. Both 
TABLE 3 | Comparison of awareness of the best course of treatment between periodontal and prosthetic treatment and the student's recognition about the effect on diseases, symptoms, and conditions.

\begin{tabular}{|c|c|c|c|c|c|c|}
\hline \multirow[t]{3}{*}{ Survey item } & \multicolumn{6}{|c|}{ Considered positive effects (\%) } \\
\hline & \multicolumn{3}{|c|}{ Before clinical training $(N=32)$} & \multicolumn{3}{|c|}{ After clinical training $(N=42)$} \\
\hline & $\begin{array}{l}\text { Periodontal } \\
\text { treatment }\end{array}$ & $\begin{array}{l}\text { Prosthetic } \\
\text { treatment }\end{array}$ & $P$-value & $\begin{array}{l}\text { Periodontal } \\
\text { treatment }\end{array}$ & $\begin{array}{l}\text { Prosthetic } \\
\text { treatment }\end{array}$ & $P$-value \\
\hline \multicolumn{7}{|l|}{ Oral: } \\
\hline Not extracted & 100 & 75.0 & $0.003^{\star \star}$ & 100 & 100 & NE \\
\hline Halitosis & 68.8 & 43.8 & 0.45 & 100 & 73.8 & $0.0004^{\star \star}$ \\
\hline \multicolumn{7}{|l|}{ Systemic diseases: } \\
\hline Obesity & 65.6 & 53.1 & $0.008^{\star *}$ & 78.6 & 69.0 & 0.32 \\
\hline Diabetes mellitus & 81.3 & 50.0 & $0.018^{*}$ & 97.6 & 71.4 & $0.0009^{\star \star}$ \\
\hline Stomach cancer & 56.3 & 46.9 & $<0.0001^{\star \star}$ & 54.8 & 40.5 & 0.19 \\
\hline Arteriosclerosis & 71.9 & 43.8 & $0.002^{\star \star}$ & 81.0 & 52.4 & $0.006^{\star \star}$ \\
\hline Cerebrovascular disorder & 65.6 & 43.8 & 0.061 & 76.2 & 52.4 & $0.023^{*}$ \\
\hline Pustulosis palmoplantaris & 25.0 & 31.3 & 0.072 & 47.6 & 35.7 & 0.27 \\
\hline Arthritis rheumatoid & 56.3 & 37.5 & $0.028^{*}$ & 69.0 & 38.1 & $0.005^{\star \star}$ \\
\hline Chronic kidney disease & 43.8 & 37.5 & $0.0008^{\star \star}$ & 59.5 & 28.6 & $0.004^{\star \star}$ \\
\hline Nonalcoholic steatohepatitis & 37.5 & 34.4 & $0.006^{\star *}$ & 47.6 & 28.6 & 0.072 \\
\hline Aspiration pneumonia & 84.4 & 59.4 & 0.37 & 97.6 & 92.9 & 0.31 \\
\hline \multicolumn{7}{|l|}{ Geriatric: } \\
\hline Eating/Swallowing function & 75.0 & 87.5 & 0.25 & 95.2 & 95.2 & 1.0 \\
\hline Eating function & 87.7 & 93.8 & 0.24 & 97.6 & 95.2 & 0.56 \\
\hline Swallowing function & 78.1 & 93.8 & $0.042^{\star}$ & 95.2 & 95.2 & 1.0 \\
\hline Walking function & 43.8 & 50.0 & $0.001^{\star \star}$ & 69.0 & 78.6 & 0.32 \\
\hline Nutritional condition & 75.0 & 84.4 & $0.002^{\star \star}$ & 100 & 100 & $\mathrm{NE}$ \\
\hline Cognitive function & 62.5 & 81.3 & $0.019^{*}$ & 97.6 & 100 & 0.31 \\
\hline \multicolumn{7}{|l|}{ Feelings of happiness: } \\
\hline Quality of life & 84.4 & 90.6 & 0.41 & 100 & 100 & NE \\
\hline Healthy life expectancy & 90.6 & 84.4 & 0.057 & 100 & 97.6 & 0.31 \\
\hline
\end{tabular}

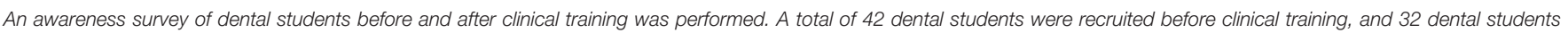

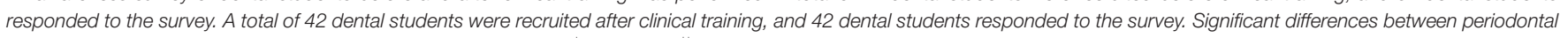
and prosthetic treatment were examined using Fisher's exact test. ", $P<0.05 ;{ }^{* *}, P<0.01$. NE, not examined. The boldface indicates the "significantly higher" results.

dental and medical students may feel that dental treatment contributes to the nutritional improvement by the mastication while eating.

Although dental students before clinical training noticed that periodontal treatment improves the outcomes of systemic diseases such as diabetes mellitus and aspiration pneumonia, the more students after clinical training noticed the significance fortunately (Table 2). In addition, a significantly higher percentage of students recognized the positive effects of prosthetic treatment on aspiration pneumonia after clinical training, despite not understanding the effects before clinical training. These results indicate that the students learned the relationship between aspiration pneumonia and periodontitis in the lectures on periodontics, but not the lectures on prosthetics in Japan. As several investigators reported previously, both periodontal and prosthetic treatment contribute to the prevention of geriatric impairment, resulting in an improvement of the patients' quality of life $(14,15)$. Importantly, the dental students after clinical training fully recognized the improvement of several geriatric factors, even such factors as walking function or cognitive function, which are connected to not only prosthetic treatment but also periodontal treatment. In geriatric hospitals, since physicians, nurses, and speechlanguage-hearing therapists play an important role in providing healthcare for elderly patients with aspiration pneumonia (16), multi-professional education courses may be more effective in improving the understanding of dental students before clinical training. An effective curriculum should be designed to enable dental students to recognize the importance of dental treatment.

Finally, the following question was considered: "Which is superior, periodontal or prosthetic treatment, for the improvement of systemic health?" As expected, most dental students both before and after clinical training felt that periodontal treatment has more positive effects than prosthetic treatment in the improvement of systemic diseases such as diabetes, arteriosclerosis, rheumatoid arthritis, and chronic kidney disease (Table 3). On the other hand, although most 
dental students before clinical training felt that prosthetic treatment has more positive effects than periodontal treatment in the improvement of geriatric factors, such as swallowing function, nutritional condition and walking function, there were no significant differences regarding the significance of periodontal and prosthetic treatments in the improvement of all geriatric factors after the completion of clinical training. This recognition could be improved by undergraduate clinical training that includes explanations of how both periodontal and prosthetic treatment contribute to improving the condition of geriatric patients.

On the basis of this survey, we want to confirm whether the undergraduate clinical training is really useful for improving the students' understanding of the clinical significance of dental treatment. This aim could be achieved by assessing understanding through pre-test and post-test one before and the other is after the clinical training. In addition, these two tests must be constructed in a way that can assess the desired cognitive level, for example, by delivering the different systemic diseases and conditions in the form of vignettes, then asking the student about them. It is crucial to assess those students in their ability to express what had been understood during the clinical training by some other methods, for example, counseling some patients who are liable to these diseases or conditions. By this way, we can assess higher order cognitive functions and some functions in the psychomotor domain as counseling.

A combination of experience gained by clinical training and evidence obtained from traditional lectures may underlie the experience- and evidence-based education (EEBE) model that is used in dentistry education. The idea that the ultimate objective of both periodontal and prosthetic treatment is to improve the quality of life of patients as they age should be conveyed to all dental students.

\section{CONCLUSION}

Both traditional lectures and clinical training help students learn in different ways. Undergraduate clinical training is more

\section{REFERENCES}

1. Soh TCF, Lim ZZ, Yip HM. Does the UK undergraduate medical curriculum prepare students in Oral and Maxillofacial Surgery? A scoping review. $\mathrm{Br} J$ Oral Maxillofac Surg. (2020) 58:1229-34. doi: 10.1016/j.bjoms.2020.06.005

2. Bhagat $\mathrm{V}$, Hoang $\mathrm{H}$, Crocombe LA, Goldberg LR. Incorporating oral health care education in undergraduate nursing curricula-a systematic review. BMC Nurs. (2020) 19:66. doi: 10.1186/s12912-020-0 0454-6

3. Moutsopoulos NM, Madianos PN. Low-grade inflammation in chronic infectious diseases: paradigm of periodontal infections. Ann NY Acad Sci. (2006) 1088:251-64. doi: 10.1196/annals.136 6.032

4. Sabharwal A, Gomes-Filho IS, Stellrecht E, Scannapieco FA. Role of periodontal therapy in management of common complex systemic diseases and conditions: an update. Periodontol 2000. (2018) 78:212-26. doi: 10.1111/prd.12226

5. van der Maarel-Wierink CD, Vanobbergen JN, Bronkhorst EM, Schols $\mathrm{JM}$, de Baat C. Oral health care and aspiration pneumonia in frail effective for increasing the students' understanding of the clinical significance of dental treatment for systemic health. An educational program of evidence-based medicine may contribute to awareness the clinical significance of dental treatment for systemic health.

\section{DATA AVAILABILITY STATEMENT}

The original contributions presented in the study are included in the article/supplementary material, further inquiries can be directed to the corresponding author/s.

\section{ETHICS STATEMENT}

The studies involving human participants were reviewed and approved by the Ethics Committee of Tokushima University Hospital (No. 3454). The patients/participants provided their written informed consent to participate in this study.

\section{AUTHOR CONTRIBUTIONS}

$\mathrm{KN}$ contributed the conception, study design, awareness survey, and wrote the manuscript. CW-M, KO, and TN contributed to the clinical education for dental students. All authors contributed to the article and approved the submitted version.

\section{FUNDING}

This study was supported by a Grant-in-Aid for Scientific Research (C) (No. 19K10131) from the Japan Society for the Promotion of Science.

\section{ACKNOWLEDGMENTS}

We thank the staff of Tokushima University for their assistance. older people: a systematic literature review. Gerodontol. (2013) 30:39. doi: 10.1111/j.1741-2358.2012.00637.x

6. Naruishi K, Nishikawa Y, Kido J, Fukunaga A, Nagata T. Relationship of aspiration pneumonia to cognitive impairment and oral condition: a cross-sectional study. Clin Oral Investig. (2018) 22:2575-80. doi: 10.1007/s00784-018-2356-7

7. Takeuchi K, Izumi M, Furuta M, Takeshita T, Shibata Y, Kageyama S. Denture wearing moderates the association between aspiration risk and incident pneumonia in older nursing home residents: a prospective cohort study. Int J Environ Res Public Health. (2019) 16:554. doi: 10.3390/ijerph16040554

8. Naruishi K, Kunita A, Kubo K, Nagata T, Takashiba S, Adachi S. Predictors of improved functional outcome in elderly inpatients after rehabilitation: a retrospective study. Clin Interv Aging. (2014) 9:213341. doi: 10.2147/CIA.S73388

9. Scannapieco FA, Cantos A. Oral inflammation and infection, and chronic medical diseases: implications for the elderly. Periodontol 2000. (2016) 72:153-75. doi: 10.1111/prd.12129

10. Monteserín-Matesanz M, Esparza-Gómez GC, García-Chías B, CereroLapiedra R. Descriptive study of the patients treated at the clinic "integrated 
dentistry for patients with special needs" at Complutense University of Madrid (2003-2012). Med Oral Patol Oral Cir Bucal. (2015) 20:e2117. doi: $10.4317 /$ medoral.20030

11. Lamster IB. Geriatric periodontology: how the need to care for the aging population can influence the future of the dental profession. Periodontol 2000. (2016) 72:7-12. doi: 10.1111/prd. 12157

12. Murai O, Sasaki D, Ando Y, Fujimura A, Oikawa H, Suwa N. Improvement of pustulosis palmaris et plantaris by periodontal infection control in a patient with chronic periodontitis. Clin Lab. (2012) 58:323-7.

13. Madianos PN, Koromantzos PA. An update of the evidence on the potential impact of periodontal therapy on diabetes outcomes. JClin Periodontol. (2018) 45:188-95. doi: 10.1111/jcpe.12836

14. Awano S, Ansai T, Takata Y, Soh I, Akifusa S, Hamasaki T. Oral health and mortality risk from pneumonia in the elderly. J Dent Res. (2008) 87:3349. doi: $10.1177 / 154405910808700418$

15. Zhang Y, Ge M, Zhao W, Hou L, Xia X, Liu X. Association between number of teeth, denture use and frailty: findings from the west China health and aging trend study. J Nutr Health Aging. (2020) 24:4238. doi: $10.1007 / \mathrm{s} 12603-020-1346-\mathrm{Z}$

16. Haresaku S, Umezaki $\mathrm{Y}$, Egashira $\mathrm{R}$, Naito $\mathrm{T}$, Kubota $\mathrm{K}$, Iino $\mathrm{H}$, et al. Comparison of attitudes, awareness, and perceptions regarding oral healthcare between dental and nursing students before and after oral healthcare education. BMC Oral Health. (2021) 21:188. doi: 10.1186/s12903-021-01554-8

Conflict of Interest: The authors declare that the research was conducted in the absence of any commercial or financial relationships that could be construed as a potential conflict of interest.

Publisher's Note: All claims expressed in this article are solely those of the authors and do not necessarily represent those of their affiliated organizations, or those of the publisher, the editors and the reviewers. Any product that may be evaluated in this article, or claim that may be made by its manufacturer, is not guaranteed or endorsed by the publisher.

Copyright $\odot 2022$ Naruishi, Wada-Mihara, Oishi and Nagata. This is an open-access article distributed under the terms of the Creative Commons Attribution License (CC $B Y)$. The use, distribution or reproduction in other forums is permitted, provided the original author(s) and the copyright owner(s) are credited and that the original publication in this journal is cited, in accordance with accepted academic practice. No use, distribution or reproduction is permitted which does not comply with these terms. 